\title{
Interpenetrating polymer networks based on cyanate ester and fluorinated ethynyl-terminated imide oligomers
}

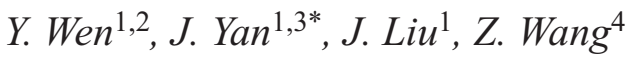 \\ ${ }^{1}$ Laboratory of Polymer Composites Engineering, Changchun Institute of Applied Chemistry, Chinese Academy of \\ Sciences, 130022 Changchun, China \\ ${ }^{2}$ University of Chinese Academy of Sciences, 100049 Beijing, China \\ ${ }^{3}$ Changzhou Institute of Energy Storage Materials and Devices, 213000 Changzhou, China \\ ${ }^{4}$ State Key Laboratory of Polymer Physics and Chemistry, Changchun Institute of Applied Chemistry, Chinese Academy \\ of Sciences, 130022 Changchun, China
}

Received 19 April 2017; accepted in revised form 26 June 2017

\begin{abstract}
Highly soluble fluorinated ethynyl-terminated imide (FETI) oligomers were prepared via a conventional one-step method in m-cresol, using 4, 4'-(hexafluoroisopropylidene) diphthalic anhydride and 2, 2'-bis(trifluoromethyl) benzidine as the monomers, and ethynylphthalic anhydride as the end-capper; then interpenetrating polymer networks (IPN) were formulated from FETI oligomers and bisphenol A dicyanate ester (BADCy) through a solvent-free procedure, and their thermal, mechanical, and dielectric properties were fully characterized. The curing mechanism was studied by model reactions using nitrogen nuclear magnetic resonance. As evidenced by differential scanning calorimetry analysis and rheological measurements, the FETI/BADCy blends exhibited lower curing temperature and shorter gelation time in comparison with pure BADCy due to the catalytic effects of ethynyl and residue amic acid groups. The properties of IPNs were fully compared with those of polycyanurate, and the results revealed that the incorporation of FETI into cyanate ester resins could significantly improve the toughness, glass transition temperatures, mechanical and dielectric properties of the resultant IPNs.
\end{abstract}

Keywords: thermosetting resins, fluorinated ethynyl-terminated imide, cyanate ester, interpenetrating polymer networks

\section{Introduction}

Cyanate esters $(\mathrm{CE})$ are a class of thermosetting resins featuring high glass-transition temperature $\left(T_{\mathrm{g}}\right)$, excellent processability, low relative permittivity and loss, low moisture absorption, low outgassing, inherent flame retardancy, good mechanical properties, and favorable compatibility with various substrates [1-4]. Thus, cyanate esters have been widely used as high performance matrix resins in the aerospace and microelectronics industries. In spite of relatively high toughness compared with other thermosets, toughening of CE resins is usually needed for highly demanding applications [5, 6]. Additionally, to achieve adequate curing extent, high curing temperature and prolonged curing time are usually required in $\mathrm{CE}$ resin systems, which could cause stress concentration and the formation of defects in the final products $[7,8]$. It is still challenging to develop CE resins with high toughness while retaining their excellent mechanical, thermal, and dielectric properties, as well as good processability.

Many research efforts have been devoted to improving the toughness of CE resins by blending them with thermosets or thermoplastics. Reactive rubbers, such as carboxyl-terminated butadiene acrylonitrile (CTBN) and amine-terminated butadiene acrylonitrile (ATBN), are effective toughening agents for CE resins. Feng et al. [9] reported that the incorporation 
of $10 \mathrm{phr}$ CTBN in CE resins led to a $200 \%$ increase in impact strength of the resultant thermosets. However, this approach lowered the thermal and mechanical properties of the resulting thermosets due to the low $T_{\mathrm{g}}$ and inferior modulus of reactive rubbers. To over these limitations, various engineering plastics with high $T_{\mathrm{g}}$ and modulus, including poly(ether sulfone)s, poly(phenylene oxide)s, poly(ether imide)s, poly(arylene ether ether ketone)s, and polyimides, were investigated as modifying additives for $\mathrm{CE}$ resins [10-14]. The fracture strengths of the blending systems were significantly improved without sacrificing thermal and mechanical properties due to the formation of micro-sized engineering plastic domains. Nevertheless, the introduction of high-molecular-weight engineering thermoplastics into the formulations gave rise to an abrupt increase in melt viscosity, which was detrimental to the resins' processability and consequently the composite properties.

An alternative approach to modifying $\mathrm{CE}$ resins is to blend them with thermosetting resins, such as epoxy (EP), bismaleimide (BMI), and polyimides. Epoxy could copolymerize with cyanate groups to yield substituted oxazolidinones. Furthermore, the hydroxyl groups existing in epoxy resins could catalyze cyanate trimerization, which led to lower curing temperatures. Thus, EP/CE blends showed improved processability and toughness compared with pure $\mathrm{CE}$ resins $[15,16]$. However, the $T_{\mathrm{g}}$, thermal stability, and dielectric properties were compromised with the addition of epoxy. Bismaleimide-triazine resin (BT resin), comprising a blend of BMI and CE resins, enjoyed the advantages of the two resin systems, possessing a combination of good processability, high $T_{\mathrm{g}}$, low relative permittivity and loss, as well as reduced moisture absorption $[17,18]$. However, the toughness of $\mathrm{BT}$ resin remained at a low level because of the inherent brittleness of BMI. Thermosets based on ethynyl- or phenylethynyl-terminated imide oligomers were inherently tough, thanks to the predominant linear chain extension during the thermal curing of reactive end groups. Meier et al. [19] investigated IPNs based on Novolac-type CE resin and phenylethynyl-terminated imide (PETI) with or without compatibilizer. The thermal properties of the resultant thermosets were similar or slightly higher than those of pure polycyanurate. Qu et al. [20] studied the curing kinetics of blends of bisphenol A dicyanate ester (BADCy) and ethynyl-terminated imide oligomers based on 2, 3, 3', 4'-biphenyltetracarboxylic dianhydride and 3, 4'-oxydianiline. Nevertheless, no significant improvements in terms of $T_{\mathrm{g}}$, tensile properties, and toughness were observed compared with pure polycyanurate, which can be contributed to the high crosslinking density, as well as the the existence of macroscopic phase separation. In this work, we report a series of IPNs based on BADCy and fluorinated ethynyl-terminated imide (FETI) oligomers. FETI oligomers were highly soluble in melting BADCy, which allowed the formulation of BADCy/FETI blends with a FETI content of up to $30 \mathrm{wt} \%$ without the aid of any solvents. The acidic ethynyl functionality and the trace amount residue amic acid group could catalyze cyanate trimerization, leading to a lower curing temperature and shorter gelation time of the resulting blends. The rigid backbone of FETI could offer the high $T_{\mathrm{g}}$, and tensile strength and modulus of the resulting thermosets. Furthermore, the incorporation of fluorine atoms could enhance the dielectric properties of the resultant polymers. The properties of IPNs were systematically studied, and the results revealed the introduction of FETI into $\mathrm{CE}$ resins gave rise to significant enhancements of toughness, $T_{\mathrm{g}}$, and mechanical and dielectric properties.

\section{Experimental}

\subsection{Materials}

BADCy was purchased from Yangzhou Tianqi Chemical Ltd. (Yangzhou, China). 4, 4'-(Hexafluoroisopropylidene) diphthalic anhydride (6FDA) and 2, 2'bis (trifluoromethyl) benzidine (TFMB) were purchased from Changzhou Sunlight Pharmaceutical co., Ltd. (Changzhou, China). 4-Ethynylphthalic anhydride (EPA) was purchased from Nexam Chemical AB (Lund, Sweden). All other reagents were obtained from Tianjin Tiantai Fine Chemical Industry Co., Ltd. 6FDA was purified by sublimation in vacuum at $260^{\circ} \mathrm{C}$ prior to use. All other chemicals were used as received unless specified.

\subsection{Oligomer and model compound synthesis}

As shown in Figure 1, FETI oligomers were prepared through a conventional one-step method in m-cresol using EPA as the end-capper, and 6FDA and TMFB as the monomers. A typical procedure for oligomer synthesis follows. 6FDA (42.203 g, $0.095 \mathrm{~mol})$, TFMB $(32.023 \mathrm{~g}, 0.100 \mathrm{~mol})$, EPA $(1.721 \mathrm{~g}$, $0.010 \mathrm{~mol})$, and $m$-cresol $(500 \mathrm{~mL})$ were charged 


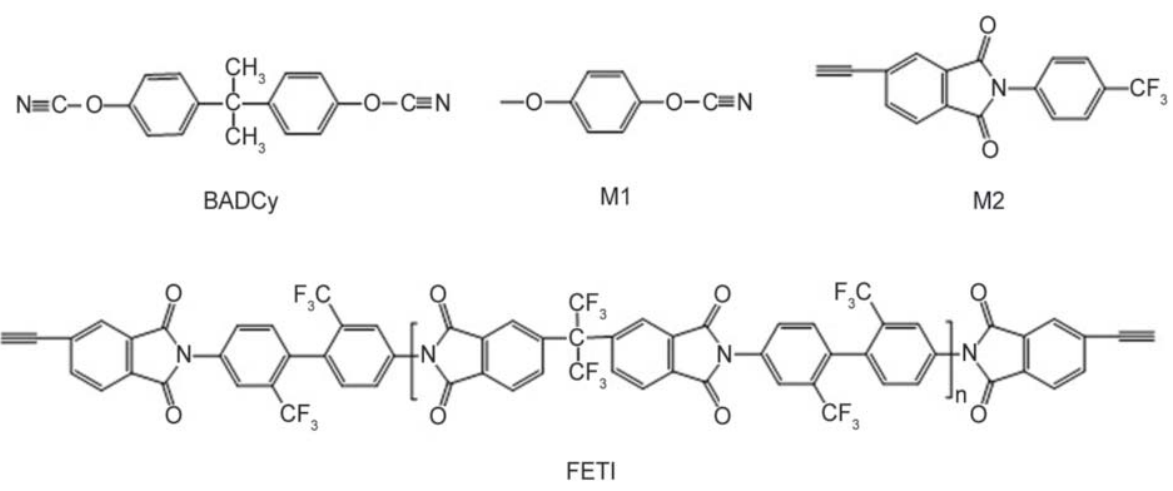

Figure 1. Structures of BADCy, FETI, and their model compounds

into a $1 \mathrm{~L}$, three-necked flask fitted with a mechanical stirrer, a condenser, and nitrogen inlet and outlet. The reaction was heated at $80^{\circ} \mathrm{C}$ for $10 \mathrm{~h}$ and then at $180^{\circ} \mathrm{C}$ for $12 \mathrm{~h}$ in nitrogen atmosphere. The byproduct, water, was removed by passing a nitrogen flow through the reactor. Upon cooling to room temperature, the viscous solution was poured into ethanol (2 L), collected by filtration, Soxhlet extracted with anhydrous ethanol for $48 \mathrm{~h}$, and dried in vacuum at $120^{\circ} \mathrm{C}$ for $24 \mathrm{~h}$ to afford an off-white solid $(67.4 \mathrm{~g}$, yield: $93.2 \%$ ). The weight average molecular weight and polydispersity for this oligomer were $29 \mathrm{~kg} \cdot \mathrm{mol}^{-1}$ and 1.68 , respectively. The oligomers were designated by their degree of polymerization, e.g. FETI-19 was the oligomer with a degree of polymerization of 19 . Model compound (M2) was prepared via a procedure similar to FETI synthesis, using 4-aminobenzotrifluoride and EPA as the raw materials. The crude products were purified by sublimation in vacuum at $180{ }^{\circ} \mathrm{C}$ (yield: $\left.12.6 \%\right) .{ }^{1} \mathrm{H}$ NMR $(400 \mathrm{MHz}$, DMSO$\left.d_{6}\right) \delta[\mathrm{ppm}]: 8.04(\mathrm{~s}, 1 \mathrm{H}), 8.00(\mathrm{~s}, 2 \mathrm{H}), 7.94(\mathrm{~d}, J=$ $8.3 \mathrm{~Hz}, 2 \mathrm{H}), 7.73$ (d, $J=8.2 \mathrm{~Hz}, 2 \mathrm{H}), 4.67$ (s, 1H). ${ }^{15} \mathrm{~N}$ NMR (61 MHz, DMSO- $\left.d_{6}\right) \delta$ [ppm]: 170.35 .

\subsection{Formulation}

Appropriate amount of FETI-19 oligomers were added to melting BADCy at $100^{\circ} \mathrm{C}$. The weight ratios of BADCy to FETI-19 were 90:10, 80:20, and 70:30. The blends were accordingly named as Blend10 , Blend-20, and Blend- 30 . The blends were stirred for $1 \mathrm{~h}$ at $100^{\circ} \mathrm{C}$ to yield homogeneous solution. Then the solution was transferred to a preheated mold, and degassed in a vacuum oven at $120^{\circ} \mathrm{C}$ for $1 \mathrm{~h}$. The blends were then cured at $150^{\circ} \mathrm{C}$ for $3 \mathrm{~h}, 170^{\circ} \mathrm{C}$ for $2 \mathrm{~h}, 190^{\circ} \mathrm{C}$ for $2 \mathrm{~h}$, and $230^{\circ} \mathrm{C}$ for $2 \mathrm{~h}$. The resultant thermosets were released from the mold at $150^{\circ} \mathrm{C}$, and then postcured at $230^{\circ} \mathrm{C}$ for $4 \mathrm{~h}$ to afford the corresponding IPNs. IPNs were classified by the
FETI-19 percentage in the resins, e.g. IPN-30 was the thermoset with a FETI-content of 30\%. Pure thermosetting polyimides were prepared by compressionmolding in a stainless steel mold with a hot press. FETI oligomers were heated to $300^{\circ} \mathrm{C}$ in 30 minutes on a hot plate. Then pressure (100 MPa) was applied, and the temperature was ramped to $380^{\circ} \mathrm{C}$ in $20 \mathrm{~min}$, and held at $380^{\circ} \mathrm{C}$ for $1 \mathrm{~h}$. The polyimides were cooled under pressure to about $200^{\circ} \mathrm{C}$, and the pressure was subsequently released. The polymers was removed from the mold and stored under ambient condition before subjected to characterization.

\subsection{Characterization}

Fourier transform infrared spectroscopy (FTIR) was performed using a Bruker VERTEX 70 spectrometer. ${ }^{1} \mathrm{H}$ NMR and ${ }^{15} \mathrm{~N}$ NMR spectra were carried out on a Bruker-400 spectrometer, using DMSO- $d_{6}$ as the solvent. Gel permeation chromatography (GPC) was conducted on a Waters 1515 GPC instrument at $35^{\circ} \mathrm{C}$ with tetrahydrofuran as the eluent. Molecular weights were determined by calibration with polystyrene standards. Differential scanning calorimetry (DSC) was conducted on a DSC Q2000 (TA Instruments). The samples were heated from 40 to $400^{\circ} \mathrm{C}$ with a heating rate of $10^{\circ} \mathrm{C} \cdot \mathrm{min}^{-1}$ and a nitrogen flow rate of $50 \mathrm{~mL} \cdot \mathrm{min}^{-1}$. Thermogravimetric analysis (TGA) was carried out on a TGA Q50 (TA Instruments). The samples were heated from 60 to $800^{\circ} \mathrm{C}$ with a heating rate of $10^{\circ} \mathrm{C} \cdot \mathrm{min}^{-1}$ and a nitrogen flow rate of $60 \mathrm{~mL} \cdot \mathrm{min}^{-1}$. Dynamic mechanical analysis (DMTA) was performed on a Q800 DMTA (TA Instruments) with a heating rate of $3{ }^{\circ} \mathrm{C} \cdot \mathrm{min}^{-1}$ and a frequency of $1.0 \mathrm{~Hz}$. Rheological measurements were conducted on an AR2000ex rheometer (TA Instruments). Tensile properties of the thermosets were measured by using an Instron material testing system (Model 5982) under a constant displacement rate of 
$2.0 \mathrm{~mm} \cdot \mathrm{min}^{-1}$ according to $\mathrm{GB} / \mathrm{T} 1040.1-2006$. The unnotched impact strength of the thermosets was determined by using a cantilever beam impact testing machine (JJ-20, Changchun, China) according to GB/T 1843-2008. Five samples were tested for each thermoset in tensile and impact strength measurments. Dielectric measurements were performed on an Agilent impedance analyzer (Agilent Technologies, USA).

\section{Results and discussion}

\subsection{Synthesis and characterization of FETI oligomers and thermosetting polyimides}

The model compound $\mathbf{M} 2$ and fluorinated ethynylterminated imide (FETI) oligomers were prepared through a conventional one-step method in m-cresol. FTIR spectrum for FETI-2 was exhibited in Figure 2. The completion of imidization was evidenced by the characteristic absorption bands at around 1780 (asymmetric $\mathrm{C}=\mathrm{O}$ stretching), 1730 (symmetric $\mathrm{C}=\mathrm{O}$ stretching), and $1370 \mathrm{~cm}^{-1}$ (C-N stretching). Meanwhile, the existence of ethynyl functionality was proved by the peak at around $3300 \mathrm{~cm}^{-1}(\mathrm{C}-\mathrm{H}$ stretching) in the FTIR spectrum and the peak at around $4.6 \mathrm{ppm}$ in ${ }^{1} \mathrm{H}$ NMR spectrum. The abovementioned results confirmed the success of $\mathbf{M} 2$ and FETI synthesis.

The curing temperature of ethynyl functionality falls in the range of $200-250^{\circ} \mathrm{C}$, which was lower than the melting temperature of ethynyl-terminated imide oligomers. Consequently, these oligomers were not suitable for the applications of matrix resins for fiberreinforced composites because of their poor processability. In this study, FETI oligomers were cured by

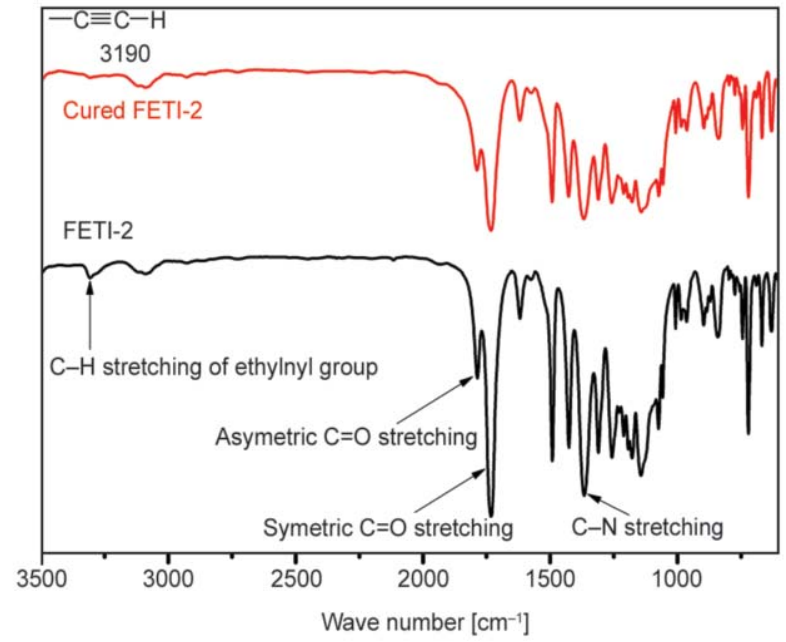

Figure 2. FTIR spectra of FETI-2 before and after cure
Table 1. $T_{\mathrm{g}}$ and impact strength of thermosets based on BADCy, FETI, and their blends

\begin{tabular}{|l|c|c|}
\hline \multicolumn{1}{|c|}{ Thermosets } & $\begin{array}{c}\boldsymbol{T}_{\mathrm{g}} \text { a } \\
{\left[{ }^{\circ} \mathbf{C}\right]}\end{array}$ & $\begin{array}{c}\text { Impact strength } \\
{\left[\mathbf{k J} \cdot \mathbf{m}^{-2}\right]}\end{array}$ \\
\hline BADCy & 297 & $24 \pm 0.6$ \\
\hline FETI-2 & 429 & $21 \pm 0.5$ \\
\hline FETI-9 & 370 & $34 \pm 1.5$ \\
\hline FETI-19 & 357 & $72 \pm 3.3$ \\
\hline FETI-2 (30\%) + BADCy (70\%) & - & $22 \pm 0.9$ \\
\hline FETI-9 $(30 \%)+$ BADCy $(70 \%)$ & - & $26 \pm 1.1$ \\
\hline FETI-19 $(30 \%)+$ BADCy $(70 \%)$ & - & $37 \pm 1.7$ \\
\hline
\end{tabular}

${ }^{a}$ Measured by DMTA with a heating rate of $3{ }^{\circ} \mathrm{C} \cdot \mathrm{min}^{-1}$

heating at $380^{\circ} \mathrm{C}$ at elevated temperature, and the properties of the resultant thermosets were characterized through DMTA and impact strength testing. As listed in Table 1, the $T_{\mathrm{g}}$ values of FETI-based thermosets increased with the decrease of the oligomers' degree of polymerization, ranging from 357 to $429^{\circ} \mathrm{C}$. On the contrary, the impact strength for thermosetting polyimides increased with the oligomers' molecular weights since the thermosets tended to became more brittle when the crosslinking densities were higher.

\subsection{Curing mechanism and preliminary screening of IPNs based on BADCy and FETI}

The curing mechanism of BADCy/FETI blends was studied by model reactions of 4-methoxyphenol cyanate ester (M1), 4-ethynyl- $N$-(4-trifluoromethyphenyl) phthalimide (M2) and their mixture. The cured products of M1, M2, and their mixtures were characterized through ${ }^{15} \mathrm{~N}$ NMR. As displayed in Figure 3,

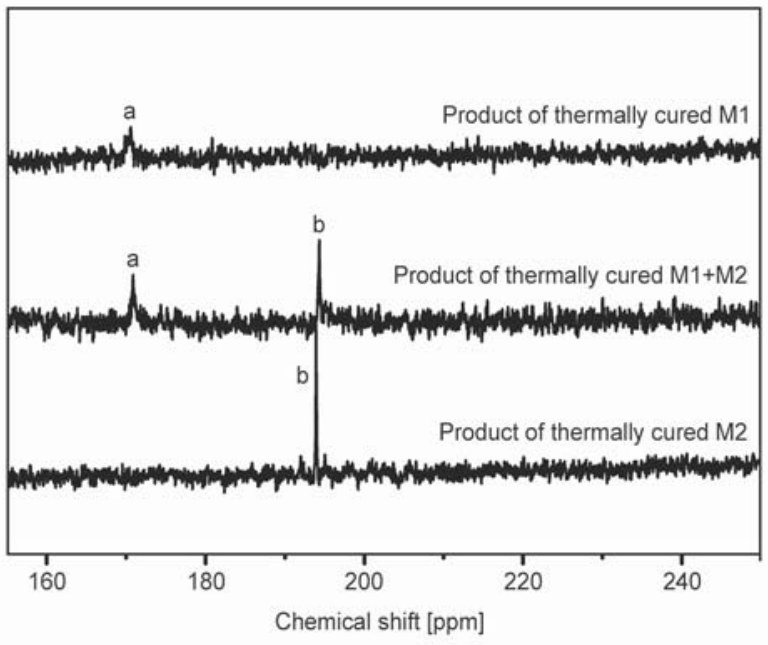

Figure 3. ${ }^{15} \mathrm{~N}$ NMR spectra of thermally cured M1, M2, and the mixture of $\mathbf{M} 1$ and $\mathbf{M} 2$ 
the peaks at around 170 and $194 \mathrm{ppm}$ in ${ }^{15} \mathrm{~N}$ NMR were assigned to the nitrogen for triazine ring and cured imide group, respectively. No new peaks appeared in the ${ }^{15} \mathrm{~N}$ NMR spectrum of the products of the mixture of M1 and M2 besides the peaks at about 170 and 194 ppm, indicating no co-reaction occurred between cyanate and ethynyl groups. Thus, BADCy/ FETI blends were expected to form physical IPNs.

Blends of FETI and BADCy were formulated by dissolving FETI in melting BADCy. Regardless of their molecular weights, FETI oligomers were highly soluble in melting BADCy monomer and oligomer because of their unique architecture combining high fluorine content, bulky hexafluoroisopropylidene linkage, and rigid but non-coplanar 2, 2'-substituted biphenyl moiety. Therefore, blends with up to $30 \%$ FETI contents were prepared without the aid of any organic solvents, which was vital for the fabrication of composites with low void content. IPNs based on FETI and BADCy were preliminarily screened by testing impact strength of the resultant thermosets with 30\% FETI contents. As summarized in Table 1, no appreciable toughening effects were achieved for IPNs containing low-molecular-weight FETI oligomers (FETI-2 and FETI-9). This phenomenon could be rationalized by the brittle nature of highly crosslinked polyimides from low-molecular-weight oligomers. In contrast, IPN based on FETI-19 showed significantly improved toughness, with impact strength of $37 \mathrm{~kJ} \cdot \mathrm{m}^{-2}$. Thus, this study focused on IPNs from FETI-19 and BADCy.

\subsection{Curing of BADCy/FETI-19 blends}

\subsubsection{FTIR and gel content}

BADCy and BADCy/FETI-19 blends were thermally cured at elevated temperature to afford the corresponding thermosets. The curing extent was characterized through gel content measurements and FTIR. As displayed in Figure 4, the strong absorption bands

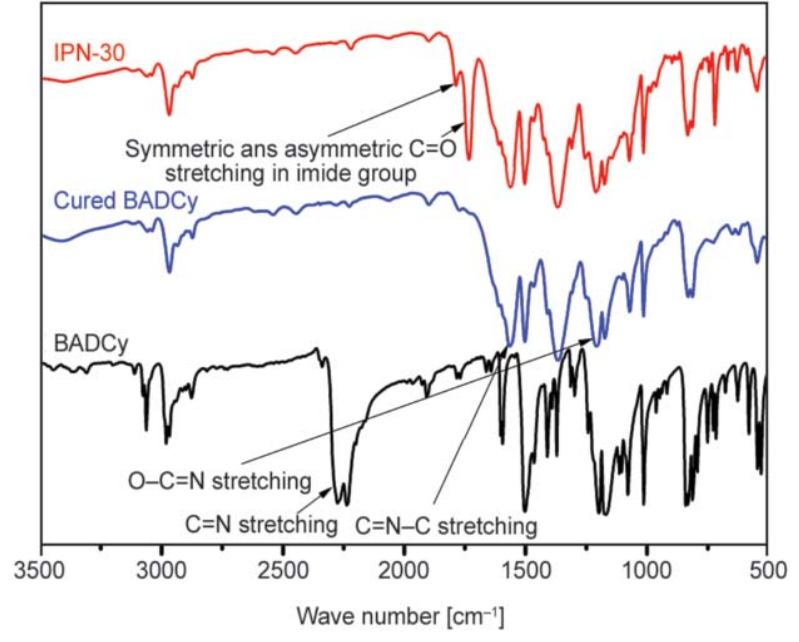

Figure 4. FT-IR spectra of BADCy, polycyanurate, and IPN-30

at around 2240 and $2270 \mathrm{~cm}^{-1}$, which corresponded to cyanate group, completely disappeared in the FTIR spectra of polycyanurate and IPN-30. Meanwhile, new peaks appeared near 1560 and $1370 \mathrm{~cm}^{-1}$, which were related to the $\mathrm{C}=\mathrm{N}-\mathrm{C}$ and $\mathrm{O}-\mathrm{C}=\mathrm{N}$ stretching in triazine ring. Furthermore, no peaks were observed at $3300 \mathrm{~cm}^{-1}$ in FTIR spectrum of IPN-30, indicating the complete curing of ethynyl groups. The abovementioned results demonstrated that polycyanurate and IPNs in this study were fully cured. The completion of the curing of ethynyl and cyanate groups was further evidenced by the high gel contents of polycyanurate and IPNs. The gel contents for all the thermosets were higher than $97 \%$ (Table 2).

\subsubsection{DSC analysis}

Figure 5 displays the DSC curves of BADCy and BADCy/FETI-19 blends. The temperatures of maximum curing rates $\left(T_{\mathrm{p}}\right)$ for BADCy and FETI-19 were 324 and $291{ }^{\circ} \mathrm{C}$, respectively, suggesting that the curing temperature for ethynyl group was lower than that of cyanate group. The exothermic peaks of the blends were broader in comparison with pure BADCy,

Table 2. Curing of BADCy, and BADCy/FETI-19 blends

\begin{tabular}{|c|c|c|c|c|c|c|}
\hline Formulation & $\begin{array}{c}T_{\mathbf{p}}{ }^{a} \\
{\left[{ }^{\circ} \mathrm{C}\right]}\end{array}$ & $\begin{array}{c}\Delta H_{0}{ }^{\mathbf{b}} \\
{\left[\mathbf{J} \cdot \mathbf{g}^{-1}\right]}\end{array}$ & $\begin{array}{c}\text { Gel content } \\
{[\%]}\end{array}$ & $\begin{array}{c}\text { Gelation time at } 200^{\circ} \mathrm{C}^{\mathrm{c}} \\
{[\mathrm{min}]}\end{array}$ & $\begin{array}{l}\text { Viscosity onset temperature } \\
\qquad\left[{ }^{\circ} \mathrm{C}\right]\end{array}$ & $\begin{array}{c}\text { Viscosity at } 120^{\circ} \mathrm{C}^{\mathrm{d}} \\
{[\mathrm{Pa} \cdot \mathrm{s}]}\end{array}$ \\
\hline BADCy & 324 & 704 & 98.8 & - & 318 & 0.002 \\
\hline Blend-10 & 312 & 631 & 98.4 & 65 & 265 & 0.056 \\
\hline Blend-20 & 290 & 562 & 97.7 & 31 & 238 & 1.120 \\
\hline Blend-30 & 273 & 497 & 97.4 & 17 & 220 & 15.350 \\
\hline
\end{tabular}

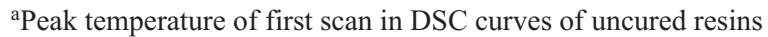

bTotal heat of curing measured by DSC

${ }^{\mathrm{c}}$ Measured by rheometry

${ }^{\mathrm{d}}$ Measured by rheometry; the viscosity was taken at a frequency of $100 \mathrm{~s}^{-1}$ 


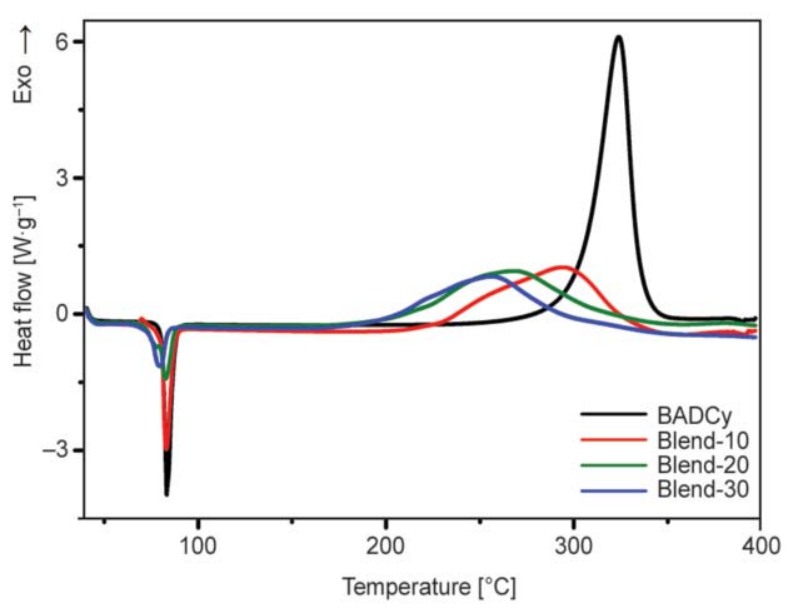

Figure 5. DSC curves of pure BADCy and BADCy/FETI19 blends

indicating that the curing reactions of the blends were relatively milder. Small but visible shoulder peaks were observed in the DSC traces of the blends, which can be attributed to the curing of ethynyl groups. The $T_{\mathrm{p}}$ values for BADCy/FETI-19 blends decreased with increasing FETI-19 contents, ranging from 273 to $312^{\circ} \mathrm{C}$. The low curing temperatures of the blends could be rationalized in the terms of the acidic ethynyl group and the trace amount of residue amic acid group. The existence of active hydrogens accelerated cyanate trimerization, resulting in the lower curing temperatures of the blends. The values of total reaction heat of curing $\left(\Delta H_{0}\right)$ were in the range of 497-704 J. $\mathrm{g}^{-1}$, decreasing with the FETI-19 content due to the relatively low $\Delta H_{0}$ value of FETI19 (11 versus $704 \mathrm{~J} \cdot \mathrm{g}^{-1}$ ).

\subsubsection{Rheological properties}

The viscosity-temperature profiles of BADCy and BADCy/FETI-19 blends are illustrated in Figure 6. The viscosities for all the resins firstly decreased with the temperature, and then increased rapidly as crosslinking happened. For BADCy/FETI-19 blends, a reasonably low melt viscosity was achieved at $150-250^{\circ} \mathrm{C}$, which provided a wide processing window for flowing resin and wetting fiber during composite fabrication. The onset temperatures for pure BADCy, Blend-10, Blend-20, and Blend-30 were $318,265,238$ and $220^{\circ} \mathrm{C}$, respectively. The lower onset temperatures for the BADCy/FETI-19 blends demonstrated that cyanate was accelerated by FETI oligomer, which was beneficial for the preparation of high quality composites. The viscosity values for BADCy and the BADCy/FETI- 19 blends at $120^{\circ} \mathrm{C}$

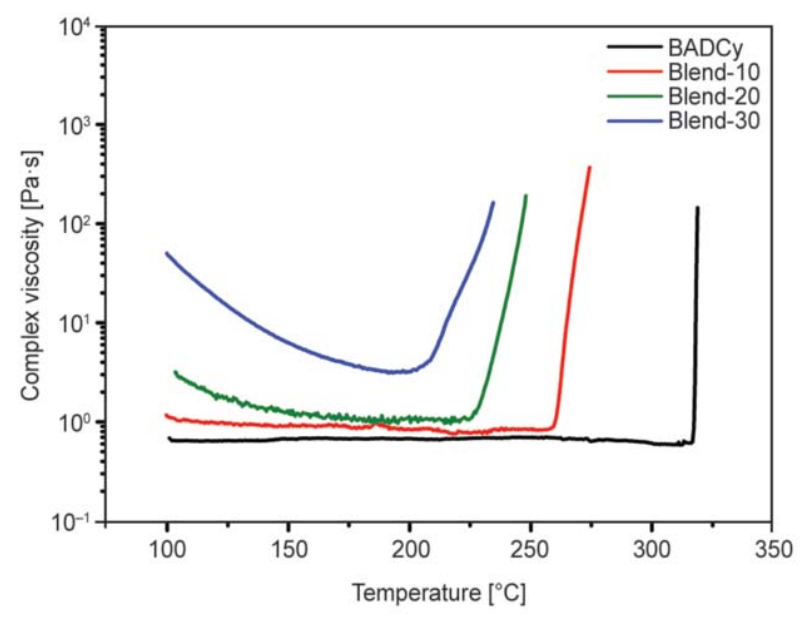

Figure 6. The viscosity-temperature profiles for BADCy and BADCy/FETI-19 blends

ranged from 0.002 to $15 \mathrm{~Pa} \cdot \mathrm{s}$, increasing with the FETI-19 contents. The viscosity of Blend-30 was considerably higher than those of other blends due to its highest FETI-19 content. The curing behavior of pure BADCy and BADCy/FETI-19 blends was also investigated by heating the resins at $200^{\circ} \mathrm{C}$ on a rheometer, and the viscosity changes over heating time are plotted in Figure 7. The viscosity of BADCy remained stable at $200^{\circ} \mathrm{C}$, and no gelation was observed after heated at $200^{\circ} \mathrm{C}$ for $3 \mathrm{~h}$. On the contrary, the viscosities of BADCy/FETI-19 blends gradually decreased until gelation happened. The viscosities of the blends abruptly increased after heated at $200^{\circ} \mathrm{C}$ for a period of time, which corresponded to the gelation time. Blend-10, Blend-20, and Blend-30 exhibited a gelation time of 65,31 , and 17 minutes at $200^{\circ} \mathrm{C}$, respectively. The shorter gelation time for BADCy/FETI-19 blends further confirmed that cyanate trimerization was catalyzed by FETI.

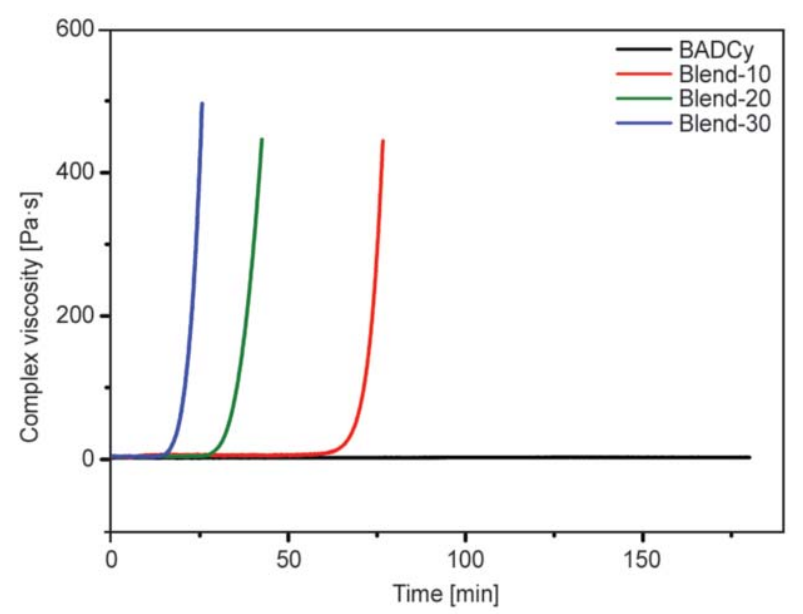

Figure 7. The viscosity changes over time for BADCy and BADCy/FETI- 19 blends at $200^{\circ} \mathrm{C}$ 


\subsection{Properties of thermosets}

\subsubsection{Thermal stability}

The thermal stability of thermosetting polycyanurate, polyimide, and their IPNs were characterized through TGA in nitrogen. As shown in Figure 8, all the polymers exhibited a three-step decomposition profile. The $5 \%$ weight loss temperature $\left(T_{5 \%}\right)$ of thermosetting polyimide was apparently higher than that of polycyanurate $\left(524\right.$ versus $424^{\circ} \mathrm{C}$ ), which could be ascribed to the degradation of isopropylidene moiety in BADCy residue at above $400^{\circ} \mathrm{C}$ [21]. The $T_{5 \%}$ values for the IPNs tended to increase with FETI content, whereas the difference was minor. These results revealed that the degradation behavior of the thermosets was predominated by the weakest segment, isopropylidene moiety in BADCy residue. The incorporation of relatively stable imide groups didn't

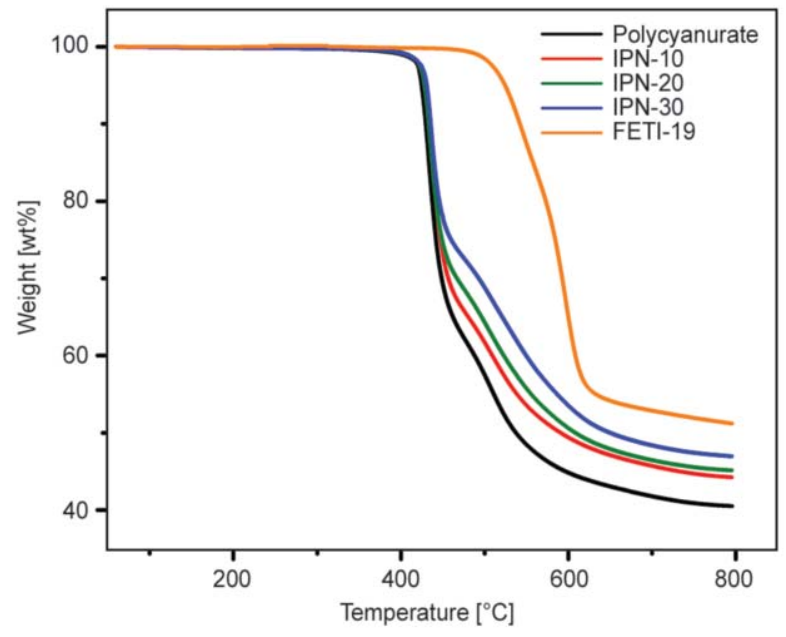

Figure 8. TGA curves of polycyanurate, polyimide, and their IPNs

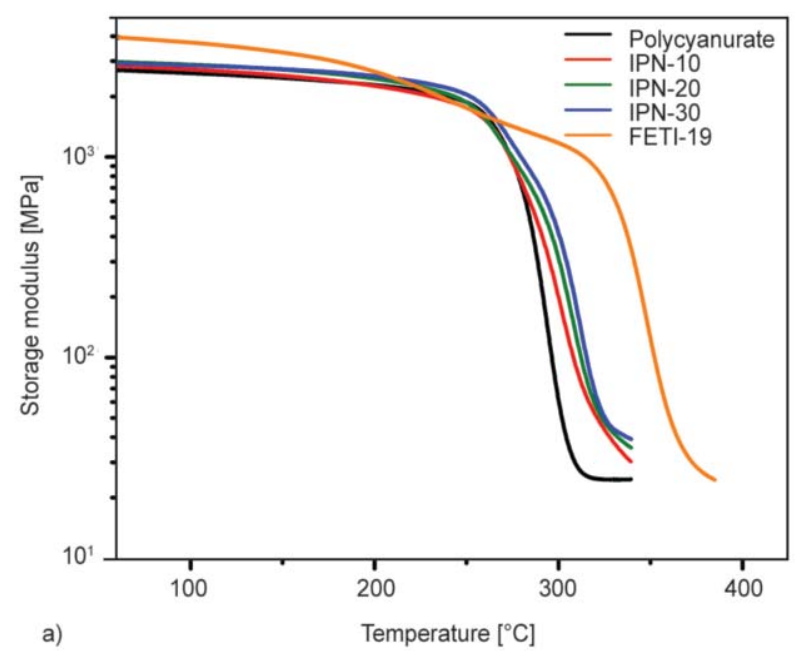

significantly improve the thermal stability of IPNs. The char yields for the thermosets showed similar trend to $T_{5 \%}$ values, ranging from 41 to $51 \%$.

\subsubsection{Glass transition temperature}

The glass transition temperatures $\left(T_{\mathrm{g}}\right)$ of thermosetting polycyanurate, polyimide, and their IPNs were determined through DMTA, and the temperature dependence of storage modulus and $\tan \delta$ are displayed in Figure 9. Single $\tan \delta$ peak was observed for all the thermosets, indicating the homogeneity of the IPNs. Theoretically, the IPNs tended to phase segregate during curing process owing to the increase of molecular weights and the decrease of the entropy of mixing. However, this tendency could be canceled by the strong interpenetration and entanglement between the two highly crosslinked networks, which accounted for the single $T_{\mathrm{g}}$ of the IPNs. The glass transition regions of the IPNs were slightly broader than that of polycyanurate because of their more complex composition. Despite its relatively lower crosslinking density, thermosetting polyimide based on FETI-19 exhibited higher $T_{\mathrm{g}}$ and initial modulus compared with polycyanurate. This phenomenon can be explained by its rigid backbone and strong inter- and intramolecular interactions stemmed from imide segments. An obvious secondary transition was observed in the DMTA curves of thermosetting polyimide, which was contributed to the relaxation of 2, 2'-substituted biphenyl segment at elevated temperature [22]. Generally, the $T_{\mathrm{gs}}$ and initial modulus of the IPNs were higher than those of pure polycyanurate, but lower than those of pure polyimide. This phenomenon could

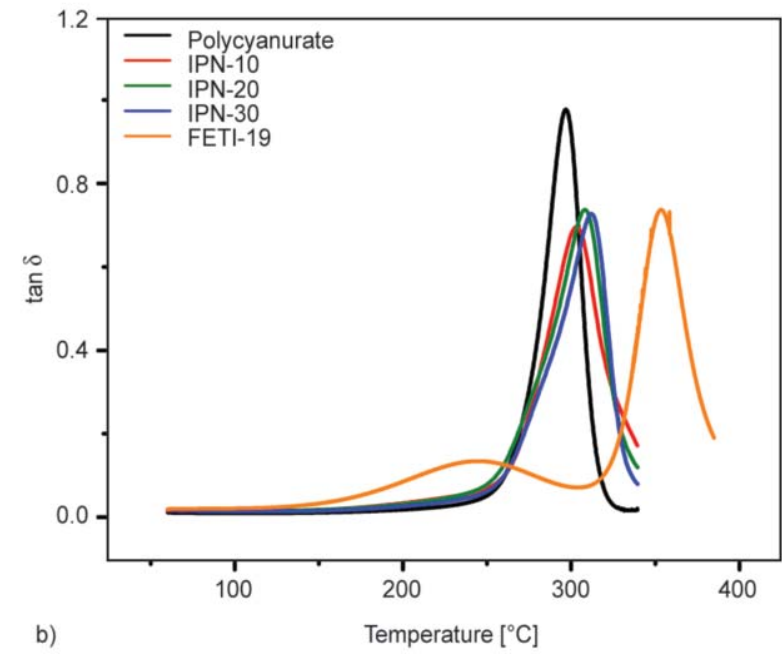

Figure 9. DMTA curves of polycyanurate, polyimide, and their IPNs a): storage modulus versus temperature, b): $\tan \delta$ versus temperature) 
be explained by the reinforcing effect of thermosetting polyimide. In addition, the high $T_{\mathrm{g}}$ and initial modulus of the IPNs were also considered as the consequence of the formation of interpenetrating networks, which constrained the chain friction and thus reduced main-chain mobility. It can be concluded that the incorporation of FETI-19 considerably improved the $\mathrm{Tg}$ and thus service temperatures of the CE resin systems.

\subsubsection{Mechanical properties}

The mechanical properties of polycyanurate, polyimide, and their IPNs were evaluated through tensile and impact strength testing, the results of which are listed in Table 3. As expected, thermosetting polyimide based on FETI-19 possessed higher tensile strength, modulus, elongation at break, and impact strength in comparison with that of polycyanurate due to its low crosslinking density, high chain rigidity, and strong inter- and intra-molecular interactions. Particularly, the impact strength of thermosetting polyimide was three times higher than that of polycyanurate. The bulky trifluoromethyl groups in the 6FDA and TFMB residue could increase the free volume of the resultant polyimide, which improved its local mobility and led to high toughness. Consequently, the introduction of 10,20 , and $30 \%$ of FETI into CE resins increased the impact strength of the resulting IPNs by 15,26 , and $56 \%$, respectively.

As expected, the mechanical properties of the IPNs fell between the values of the two pure thermosets. Especially, the tensile strength, modulus, and elongation at break for IPN-30 increased by 25,41 , and 20\% compared with pure polycyanurate, respectively. Besides the toughening effect of FETI-19, the interlocked chain entanglement between polycyanurate and polyimide networks also played an important role in the enhancements of mechanical properties. More energy was required to propagate a crack in the two discrete networks that interpenetrated or entangled closely with each other, leading to higher crack tolerance under tensile loading. This phenomenon was also observed in other IPN systems [23-25]. It is worth noting that the introduction of FETI-19 into polycyanurate simultaneously improved the tensile strength, modulus, and toughness, which is highly desired for the fabrication of high performance composites.

\subsubsection{Relative permittivity}

The relative permittivity of polycyanurate, polyimide, and their IPNs is compared in Figure 10. The low polarity of $\mathrm{C}-\mathrm{F}$ bond and non-coplanar architecture of thermosetting polyimide gave rise to a relatively low relative permittivity in comparison with pure polycyanurate. As expected, the relative permittivity for the IPNs fell between those of pure polyimides and pure polycyanurate, and decreased with increasing FETI-19 contents. Moreover, the relative permittivity for all thermosets decreased steadily with the frequency due to the decrease of net polarization. The low relative permittivity of the IPNs was beneficial for the applications in the microelectronics and aerospace industries.

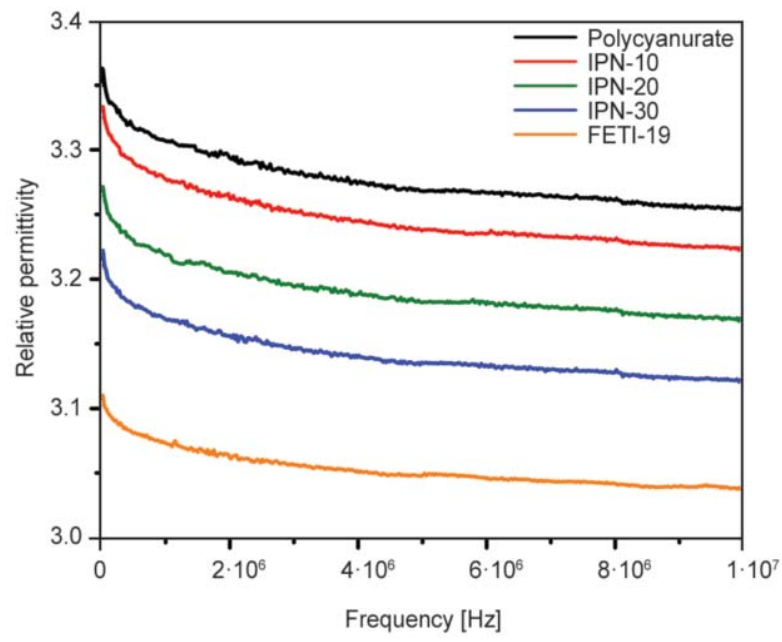

Figure 10. Relative permittivity as a function of frequency for polycyanurate, polyimide and their IPNs

Table 3. Thermal and mechanical properties of polycyanurate, polyimide, and their IPNs

\begin{tabular}{|l|c|c|c|c|c|c|c|}
\hline Thermosets & $\begin{array}{c}\boldsymbol{T}_{\mathbf{g}} \mathbf{a} \\
{\left[{ }^{\circ} \mathbf{C}\right]}\end{array}$ & $\begin{array}{c}\boldsymbol{T}_{\mathbf{5} \%}{ }^{\mathbf{b}} \\
{\left[{ }^{\circ} \mathbf{C}\right]}\end{array}$ & $\begin{array}{c}\mathbf{C h a r ~ y i e l d ~}^{\mathbf{b}} \\
{[\mathbf{\%}]}\end{array}$ & $\begin{array}{c}\text { Tensile strength } \\
{[\mathbf{M P a}]}\end{array}$ & $\begin{array}{c}\text { Tensile modulus } \\
{[\mathbf{G P a}]}\end{array}$ & $\begin{array}{c}\text { Elongation at break } \\
{[\mathbf{\%}]}\end{array}$ & $\begin{array}{c}\text { Impact strength } \\
{\left[\mathbf{k J} \cdot \mathbf{m}^{-\mathbf{2}}\right]}\end{array}$ \\
\hline BADCy & 297 & 425 & 41 & $76 \pm 2.7$ & $3.0 \pm 0.15$ & $2.9 \pm 0.08$ & $24 \pm 0.6$ \\
\hline IPN-10 & 303 & 428 & 44 & $87 \pm 1.7$ & $3.2 \pm 0.12$ & $3.4 \pm 0.15$ & $27 \pm 1.3$ \\
\hline IPN-20 & 308 & 428 & 45 & $91 \pm 3.1$ & $3.7 \pm 0.17$ & $3.4 \pm 0.12$ & $30 \pm 1.4$ \\
\hline IPN-30 & 312 & 431 & 47 & $95 \pm 3.5$ & $4.3 \pm 0.16$ & $3.5 \pm 0.17$ & $37 \pm 1.7$ \\
\hline FETI-19 & 357 & 524 & 51 & $104 \pm 5.1$ & $4.4 \pm 0.19$ & $3.7 \pm 0.11$ & $72 \pm 3.3$ \\
\hline
\end{tabular}

${ }^{\mathrm{a}}$ Measured by DMTA with a heating rate of $3{ }^{\circ} \mathrm{C} \cdot \mathrm{min}^{-1}$

${ }^{\mathrm{b}} 5 \%$ weight loss temperature, measured by TGA with a heating rate of $10^{\circ} \mathrm{C} \cdot \mathrm{min}^{-1}$ 


\section{Conclusions}

In conclusion, a series of IPNs were produced from cyanate ester and fluorinated ethynyl-terminated imide oligomers via a solvent-free procedure. As evidenced by ${ }^{15} \mathrm{~N}$ NMR, no copolymerization occurred between cyanate and ethynyl groups. Compared with pure BADCy, BADCy/FETI-19 blends showed much lower curing temperature and shorter gelation time due to the existence of acidic ethynyl functionality and trace amount of residue amic acid in FETI. The thermal, mechanical, and dielectric properties were dramatically enhanced by the incorporation of FETI. The IPNs exhibited a glass transition temperature of $303-312^{\circ} \mathrm{C}$, impact strength of $27-37 \mathrm{~kJ} \cdot \mathrm{m}^{-2}$, tensile strength of $87-95 \mathrm{MPa}$, modulus of $3.2-4.3 \mathrm{GPa}$, and relative permittivity of 3.15-3.25. These enhancements could be rationalized by the unique architecture of FETI, which combined the structural characteristics of high fluorine content, high chain rigidity, low crosslinking density, and strong inter- and intramolecular interactions. The IPNs in this work could be potentially utilized in the applications of high temperature adhesives and fiber-reinforced composites due to excellent integrated properties and good processability. This work provided some insights on how to develop modified CE resins with high toughness and low curing temperature without compromising their excellent thermal, mechanical, and dielectric properties.

\section{Acknowledgements}

The authors express their thanks to the National Science Foundation of China (No. 51473157) and Key Research and Development Program of Jiangsu Province (No. BE2015008-1) for their financial supports.

\section{References}

[1] Fang T., Shimp D. A.: Polycyanate esters: Science and applications. Progress in Polymer Science, 20, 61-118 (1995).

https://doi.org/10.1016/0079-6700(94)E0006-M

[2] Hamerton I., Hay J. N.: Recent developments in the chemistry of cyanate esters. Polymer international, 47, 465-473 (1998).

https://doi.org/10.1002/(SICI) 1097 0126(199812)47:4<465::AID-PI88 >3.0.CO;2-S
[3] Nair C. P. R., Mathew D., Ninan K.: Cyanate ester resins, recent developments. in 'New polymerization techniques and synthetic methodologies; Advances in polymer science' (eds.: Biswas M., Capek I., Chern CS., Mathew D., Nair C. P. R., Ninan K. N., Ray S. S.) Vol 155, 1-99 (2001).

https://doi.org/10.1007/3-540-44473-4_1

[4] Dudiuk H., Goodman S. H.: Handbook of thermoset plastics. Elsevier, Amsterdam (2014).

[5] Gao R., Gu A. J., Liang G., Dai S., Yuan L.: Properties and origins of high-performance poly(phenylene oxide)/ cyanate ester resins for high-frequency copper-clad laminates. Journal of Applied Polymer Science, 121, 1675-1684 (2011). https://doi.org/10.1002/app.33745

[6] Kinloch A. J., Taylor A. C.: The toughening of cyanateester polymers, Part I Physical modification using particles, fibres and woven-mats. Journal of Materials Science, 37, 433-460 (2002). https://doi.org/10.1023/A:1013735103120

[7] Chen C-C., Don T-M., Lin T-H., Cheng L-P.: A kinetic study on the autocatalytic cure reaction of a cyanate ester resin. Journal of Applied Polymer Science, 92, 3067-3079 (2004).

https://doi.org/10.1002/app.20314

[8] Deng Y., Martin G. C.: Diffusion phenomena during cyanate resin cure. Polymer, 37, 3593-3601 (1996). https://doi.org/10.1016/0032-3861(96)00168-1

[9] Feng Y., Fang Z., Gu A.: Toughening of cyanate ester resin by carboxyl terminated nitrile rubber. Polymers for Advanced Technologies, 15, 628-631 (2004). https://doi.org/10.1002/pat.519

[10] Zhao L., Yuan L., Liang G., Gu A.: Novel tough and thermally stable cyanate ester resins with high flame retardancy, low dielectric loss and constant based on a phenolphthalein type polyarylether sulfone. RSC Advances, 5, 58989-59002 (2015). https://doi.org/10.1039/c5ra10670b

[11] Yuan L., Huang S., Hu Y., Zhang Y., Gu A., Liang G., Chen G., Gao Y., Nutt S.: Poly(phenylene oxide) modified cyanate resin for self-healing. Polymers for Advanced Technologies, 25, 752-759 (2014). https://doi.org/10.1002/pat.3290

[12] Zhan G., Yu Y., Tang X., Tao Q., Li S.: Further study of the viscoelastic phase separation of cyanate ester modified with poly(ether imide). Journal of Polymer Science Part B: Polymer Physics, 44, 517-523 (2006). https://doi.org/10.1002/polb.20709

[13] Srinivasan S. A., McGrath J. E.: Amorphous phenolphthalein-basedpoly(arylene ether) modified cyanate ester networks: 1. Effect of molecular weight and backbone chemistry on morphology and toughenability. Polymer, 39, 2415-2427 (1998). https://doi.org/10.1016/S0032-3861(97)00598-3 
[14] Iijima T., Kaise T., Tomoi M.: Modification of cyanate ester resin by soluble polyimides. Journal of Applied Polymer Science, 88, 1-11 (2003).

https://doi.org/10.1002/app.11492

[15] Liang G., Zhang M.: Enhancement of processability of cyanate ester resin via copolymerization with epoxy resin. Journal of Applied Polymer Science, 85, 23772381 (2002).

https://doi.org/10.1002/app.10872

[16] Lin C. H.: Synthesis of novel phosphorus-containing cyanate esters and their curing reaction with epoxy resin. Polymer, 45, 7911-7926 (2004).

https://doi.org/10.1016/j.polymer.2004.09.023

[17] Fan J., Hu X., Yue C. Y.: Interpenetrating polymer networks based on modified cyanate ester resin. Plastics, Rubber and Composites, Macromolecular Engineering, 30, 448-454 (2001). https://doi.org/10.1179/146580101322913338

[18] Gu A.: High performance bismaleimide/cyanate ester hybrid polymer networks with excellent dielectric properties. Composites Science and Technology, 66, 1749 1755 (2006).

https://doi.org/10.1016/j.compscitech.2005.11.001

[19] Meier C., Parlevliet P., Döring M.: Interpenetrating polymer networks formed by cyanate esters and phenylethynyl-terminated imides. High Performance Polymers, 29, 556-568 (2017).

https://doi.org/10.1177/0954008316653996

[20] Qu C-Y., Xiao W., Wang D., Liu C., Li H.: Curing kinetics and properties of ethynyl terminated polyimide and cyanate ester sequential interpenetrating polymer network system (in Chinese). Polymer Materials Science and Engineering, 32, 83-89 (2016). https://doi.org/10.16865/j.cnki.1000-7555.2016.02.015
[21] Ramirez M. L., Walters R., Lyon R. E., Savitski E. P.: Thermal decomposition of cyanate ester resins. Polymer Degradation and Stability, 78, 73-82 (2002). https://doi.org/10.1016/S0141-3910(02)00121-0

[22] Arnold F. E., Bruno K. R., Shen D. X., Eashoo M., Lee C. J., Harris F. W., Cheng S. Z. D.: The origin of $\beta$ relaxations in segmented rigid-rod polyimide and copolyimide films. Polymer Engineering and Science, 33, 1373-1380 (1993). https://doi.org/10.1002/pen.760332102

[23] Wang Y., Kou K., Wu G., Zhuo L., Li J., Zhang Y.: The curing reaction of benzoxazine with bismaleimide/ cyanate ester resin and the properties of the terpolymer. Polymer, 77, 354-360 (2015). https://doi.org/10.1016/j.polymer.2015.09.059

[24] Fan J., Hu X., Yue C. Y.: Dielectric properties of selfcatalytic interpenetrating polymer network based on modified bismaleimide and cyanate ester resins. Journal of Polymer Science Part B: Polymer Physics, 41, 11231134 (2003). https://doi.org/10.1002/polb.10445

[25] Jena R. K., Yue C. Y., Sk M. M., Ghosh K.: A novel high performance bismaleimide/diallyl bisphenol A (BMI/DBA)-epoxy interpenetrating network resin for rigid riser application. RSC Advances, 5, 79888-79897 (2015). https://doi.org/10.1039/c5ra14474d 